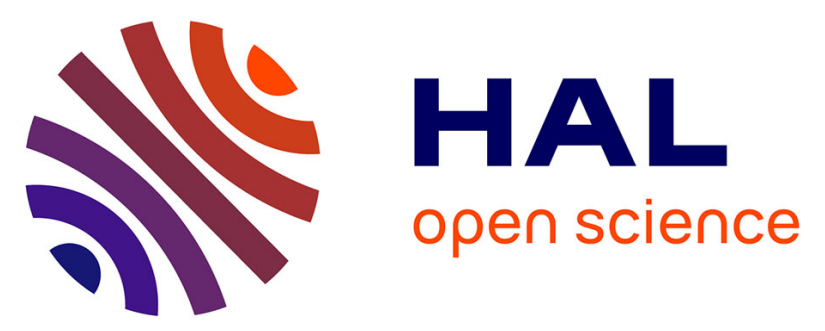

\title{
A Dual Perspective Workflow to Improve Data Collection for Maintenance Delivery: An Industrial Case Study
}

\author{
Roberto Sala, Fabiana Pirola, Emanuele Dovere, Sergio Cavalieri
}

\section{To cite this version:}

Roberto Sala, Fabiana Pirola, Emanuele Dovere, Sergio Cavalieri. A Dual Perspective Workflow to Improve Data Collection for Maintenance Delivery: An Industrial Case Study. IFIP International Conference on Advances in Production Management Systems (APMS), Sep 2019, Austin, TX, United States. pp.485-492, 10.1007/978-3-030-30000-5_60 . hal-02419239

\section{HAL Id: hal-02419239 \\ https://hal.inria.fr/hal-02419239}

Submitted on 19 Dec 2019

HAL is a multi-disciplinary open access archive for the deposit and dissemination of scientific research documents, whether they are published or not. The documents may come from teaching and research institutions in France or abroad, or from public or private research centers.
L'archive ouverte pluridisciplinaire HAL, est destinée au dépôt et à la diffusion de documents scientifiques de niveau recherche, publiés ou non, émanant des établissements d'enseignement et de recherche français ou étrangers, des laboratoires publics ou privés. 


\title{
A dual perspective workflow to improve data collection for maintenance delivery: an industrial case study
}

\author{
Roberto Sala ${ }^{1[0000-0001-7671-6927]}$, Fabiana Pirola ${ }^{10000-0003-4633-7568]}$, Emanuele Dovere ${ }^{1}$, \\ Sergio Cavalieri ${ }^{1[0000-0002-7598-0379]}$ \\ ${ }^{1}$ University of Bergamo, Department of Management, Information and Production Engineer- \\ ing, Viale Marconi, 5, Dalmine (BG), 24044, Italy \\ roberto.sala@unibg.it
}

\begin{abstract}
Due to the commodisation and globalization of the markets, manufacturing companies have been pursuing new business models based on productservice bundles, which in literature have been investigated under the broad term of Product-Service Systems (PSS). Efficient provision of PSS is not immediate since it requires as a first condition a deep integration of product and service components and the related delivery processes. As regards durable equipment, maintenance is one of the most relevant and common services offered to the market. The identification of the best maintenance policy, and the expected improvement of availability and productivity of the industrial asset depends upon the knowledge, cognition, and expertise that the provider has on the machine and the related operating conditions. With this regard, it is fundamental to wisely collect and analyze data related to the machine and its delivery process, extracting useful information guiding the policy selection. By investigating the case of a durable equipment manufacturer, the paper focuses on the problem related to the creation of a proper engineering process and data infrastructure for supporting a gradual and robust transition towards a PSS-based business model. A dual perspective vision for ensuring a continuous improvement of maintenance services is proposed and discussed, based on a cross-analysis of the on-field collected data from the industrial asset and the maintenance delivery processes.
\end{abstract}

Keywords: Maintenance, Product-Service Systems (PSS), Data Collection, Industry 4.0.

\section{$1 \quad$ Introduction}

Commodisation of the markets has forced manufacturing companies to explore new strategies for enriching their product offering with additional services in order to differentiate themselves from global competitors and to open new market niches. The advent and consolidation of key technologies positioned under the umbrella of Industry 4.0 (I4.0) have undoubtedly provided an important leverage for improving their processes and fostering their transition towards the adoption of new business models, based on the provision of integrated bundles of products and related services. This phenomenon has been extensively and deeply investigated in literature under different terms, in 
a first instance as servitisation strategy and provision of Product-Service Systems (PSS) [1].

However, despite the presumed benefits deriving from a long-standing relation and fidelisation with the client base and a consequent expected profit increase, the transition from a product-centric to a PSS-based offering is not so seamless. Integration of product and services must be designed and engineered since the first conceptual stages, properly customized in order to create real value within the customer's processes, but, at the same time, efficiently standardized in order to avoid being trapped in the service paradox [2].

Hence, PSS providers need to adopt suitable approaches and to invest in enabling technologies to support PSS delivery both from a strategical and an operational point of view. One of the most relevant services that can benefit from the introduction of I4.0 technologies is undoubtedly maintenance, whose delivery is subjected to provider's capabilities, competencies, and knowledge. Depending on the maintenance policy offered, and technology adopted, companies must deal with different benefits and risks. The provision of preventive or predictive based contracts, though a potential business opportunity for a service provider, can turn out in higher risks in terms of emerging operational costs (reflecting contract penalties) and reputational losses.

In order to address this issue, this paper proposes a workflow and the related methods for maintenance process improvement crossing data from the asset and from the maintenance provision processes. Then, it describes its application in a manufacturing company, producing durable equipment, that is moving from the provision of corrective and preventive maintenance services towards the offering of a more distinctive PSS offering. In particular, the paper focuses on the initial phase of the workflow, putting emphasis on the need to assess and deploy a standard procedure to collect maintenance data from the field and from the technicians delivering the maintenance interventions to acquire the proper knowledge and capabilities before proposing more challenging services.

The paper is structured as follows: Section 2 shortly introduces the context and proposes a workflow for maintenance process improvement. Section 3 deals with the case study. Eventually, Section 4 concludes the paper summarizing the results from the case study, the main limitations and delineating future researches.

\section{Maintenance delivery process improvement}

Product-Service System is based on the joint sale of products and services aimed at satisfying specific customer needs [3] ranging from a transactional Product-Oriented to a more Use-Oriented and Result-Oriented relationship with the customer [4, 5]. As mentioned earlier, the simple juxtaposition of products and services is not sufficient to guarantee a prolific PSS delivery [2, 6], especially if a supporting technological and organisational infrastructure is not available. In this regard, [7] state that the adoption of new technologies, such as I4.0 ones (e.g. cyber-physical systems, big data, simulation), can foster the transition towards PSS offering, reducing the risk of incurring in the service paradox trap and increasing the efficiency of service delivery. As [8-10] 
affirm, the integration of technologies into PSS can support and enhance the delivery of more effective services but this is subordinated to the definition of a formalized approach to the PSS delivery.

Given the possibilities offered by I4.0 technologies in terms of data generation, the approach should be based on data collection [11], management [12], and exploitation [13]. In particular, it should take into account product and service components, considering the data generated both during the product usage and during the service delivery process [14]. Regarding product components, a deep knowledge of the asset working conditions is crucial for the definition of the most suitable maintenance policy. In fact, while the vendor knows its machine from the design phase, he does not know its behavior under the user's operating conditions. This would not be possible without the availability of field data and their interpretation and translation into knowledge for predicting future states of machines. On the other hand, the service component entails all the knowledge related to how the service (i.e. maintenance) is provided to customers, mainly in terms of time, costs, objects and resources used. In both cases a data collection strategy is essential to sort and extract only useful data, guaranteeing at the same time a certain quality in data collection [11]. This is necessary also to favor the following data integration phase, which is a challenging task due to problems that may arise when data collected from different sources have to be integrated [12]. A formalized approach to data collection and management facilitates data processing, favoring the extraction of useful information from the dataset under analysis [13].

Starting from these remarks, Fig. 1 proposes a dual perspective workflow for ensuring a maintenance delivery continuous improvement process based on the analysis of data related to industrial asset and to its maintenance process.

From the machine perspective, the first action consists in the identification of the critical components of the asset by using some consolidated techniques such as the Failure Modes, Effects and Criticality Analysis (FMECA) [15]. Then, depending on the critical components identified, technical data should be continuously gathered from the asset in working conditions. Then, methods such as Root Cause Analysis (RCA) and Machine Learning (ML) techniques would allow to infer the current machine health status and predetermine the Remaining Useful Life (RUL) of the components [16, 17].

From the process perspective, a first analysis of the $a s$-is service delivery workflow would allow to derive the main process criticalities. Then, according to the maintenance policy adopted, a strategy for collecting data related to the intervention should be designed and implemented.

Once collected, data from products and processes should be cross-analyzed to extract valuable information on maintenance delivery. In particular, the analysis of data related to components' failure along with maintenance delivery process would allow an update of the asset component criticality. This update would directly impact the maintenance policies adopted by the company and, thus, their delivery process. For example, it might emerge the need for more frequent maintenance actions on certain components due to the length of maintenance intervention, previously underestimated, or to the time required to retrieve spare parts. On the contrary, it might arise the possibility to reduce the frequency of the maintenance intervention, thanks to an upgrade of the technicians' expertise or to the availability of new diagnostics tools. Thanks to the information 
emerging from the cross analysis, corrective measures should be adopted both on the asset and on the process side. In addition, based on the feedbacks from the field, also components and machines may be re-engineered to make them more reliable and able to sustain different working conditions.

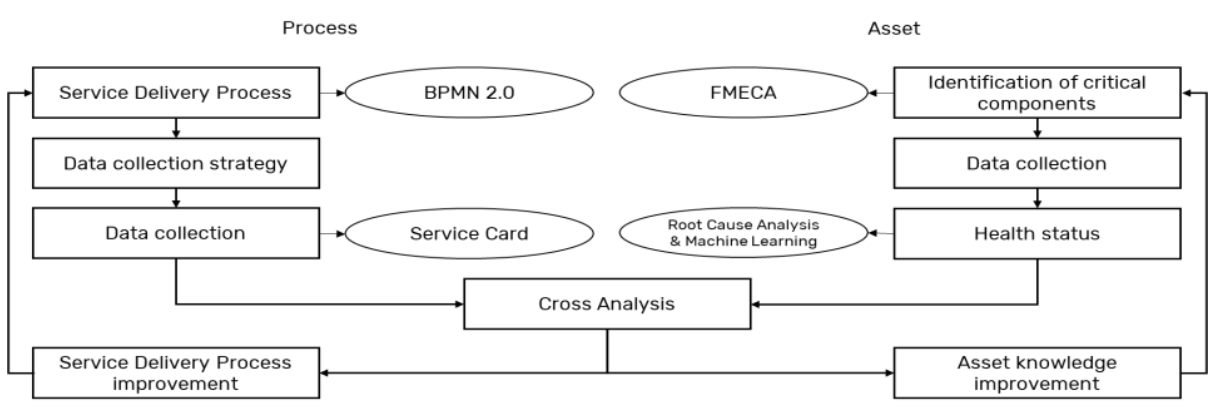

Fig. 1. The dual perspective workflow for maintenance delivery improvement

\section{The Case Study}

The case study has been carried out in the context of the PROMETE $\varnothing$ project (funded by Lombardia region) in one of the partner companies,Balance Systems (in short BS), an Italian company founded in 1975 and operating worldwide. Its core business areas are related to the production of balancing machines for rotary components and the development of process control systems for machine tools. Traditionally focused on the technological excellence of their machines, the company is enriching its solutions with service components in order to come along with the increasing and challenging requests from the markets.

To approach this transition, BS is trying to improve its maintenance provision creating a structured knowledge at both product and process level, leveraging on data acquisition, management, and processing. The definition of a formalized way to handle and create knowledge and wisdom on the process is a necessary step for the company moving towards a PSS business model. To this purpose, the workflow described in Fig. 1 has been applied to the company following a gradual multi-step approach, which is still underway. Specifically, BS has been focusing on the first three steps of the product and process improvement, which were carried out in parallel.

Within the project, two researchers have carried out multiple semi-structured interviews to collect data related to the asset and the current maintenance delivery process. Information has been then used to define a clear picture of the activities currently performed and the way information collected during and after maintenance were used and shared inside the company.

Regarding the asset, the company started applying a basic FMECA analysis. A pilot project has been carried out on one machine. Since BS machines are made up by standard groups, which are assembled differently in accordance with customer requirements, the company will be able to easily extend the FMECA analysis to other machine configurations. The purpose behind the FMECA application has been to analyze in depth 
the machine's structure and identify the main causes and effects for each component failure. To do so, a team composed by researchers and company experts has performed the machine's functional breakdown starting from the main working groups and ending with the single components. For each component, a list of possible failures and causes has been created. Following, the company experts have evaluated each component in terms of failure's Severity (S), Detectability (D) and Probability (P). The multiplication of the three factors has led to the definition of the Risk Priority Number (RPN), used to prioritize the risks deriving from each component failure.

Regarding the process, the company started from the analysis of the current maintenance delivery process (as is) that has been mapped using BPMN 2.0. From the interviews with the Service Engineering Supervisor, it has emerged that BS offering includes both corrective and preventive maintenance interventions. The analysis of the $a s$ is processes has led to the identification of several issues. One of the first criticalities emerged in the corrective maintenance is in the diagnostic phase, where a lack of knowledge on failure causes and effects often lead to a maintenance delivery slowdown. Other criticalities have been found in the scheduling phase, where multiple iterations are required to select the technician due to difficulties in matching customer requirements with technician skills and availability. Regarding preventive maintenance, criticalities are mainly related to intervention scheduling, due to the poor exploitation of data collected from the process, caused by an ineffective data collection strategy. Indeed, during the maintenance delivery, BS technicians used to fill out a form in an electronic sheet, created in Microsoft Excel ${ }^{\circledR}$, called Service Card, to report the information on the maintenance activity. The previous version of the Service Card was not user-friendly; technicians used to fill it out wrongly or partially. For this reason, information was used only for the final quotation to customers but not to generate new knowledge on maintenance. To address this issue, the Service Card has been re-engineered to simplify the filling phase. Moreover, to improve data collection, and to facilitate the analysis of critical components, the FMECA has been used as an input for the Service Card. The new version, with drop-down menus, guides the technician while specifying the critical components and entering the information of failure causes and relative fixing actions. In the scope of favoring data analysis, data extraction, storage, and management have been reconfigured, and a specific database has been created. In particular, since the efficiency of the maintenance service offering is bonded to the ability to collect and analyze historical data, the following data are now collected through the Service Card (Fig. 2): (i) general data of the client and kind of manufacturing process; (ii) information related to machines that underwent maintenance operation; (iii) hours and pieces worked by the equipment before breaking; (iv) the problem identified by the technician; (v) the spare parts used to fix it; (vi) the time spent by the technician on the machine.

This has led to the possibility to improve the knowledge of maintenance interventions (length, problems, spare parts used) that can be used for multiple purposes: updating maintenance plans, upgrading design of machines, rearranging spare parts management, improving service offering and delivery, etc. to obtain benefits both on asset and process sides. 
BS can now use data collected from maintenance interventions to extract relevant information. For instance, the engineering department is now able to analyze failures mode in those components most subjected to failures, as identified through the FMECA.

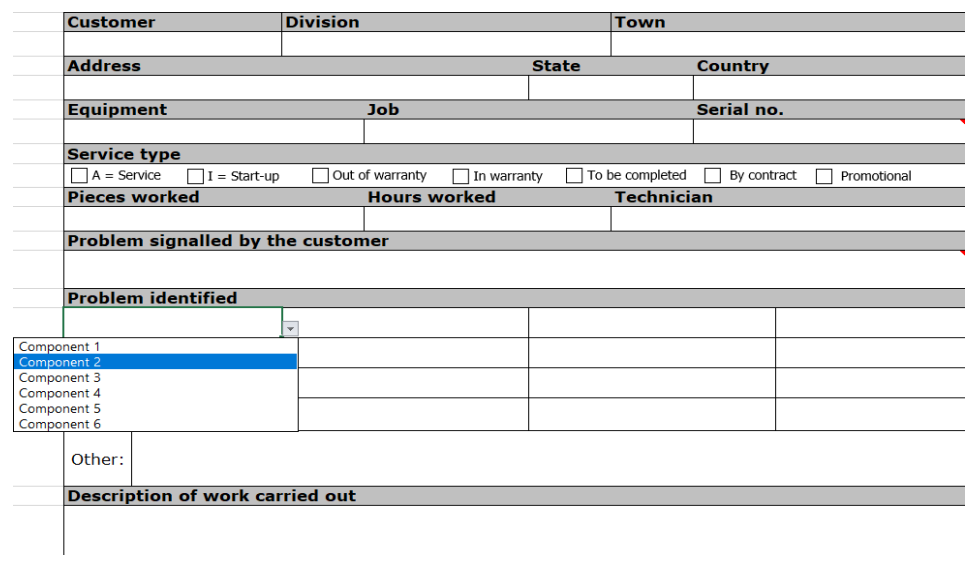

Fig. 2. An excerpt of the upgraded version of the Service Card adopted in BS

As an example, the horizontal axis belt has been recognized as one of the most critical components; for this reason, more in-depth analyses have been carried out on the belt and on other components that were discovered critical. Data related to the power absorption when the horizontal axis belt was at the right tensioning have been collected. Then, the belt tensioning has been changed several times to collect new data on power absorption. The aim of this procedure was to collect data on the right and wrong power absorption to identify useful patterns that could be used to detect problems during the machine worktime. In particular, four ML classification techniques (Multinomial Logit, Discriminant Analysis, K-neighbor, and Neural Networks) have been used to analyze the dataset to understand if they could be used in this scope and to identify the one with the better performance.

Information collected on customers such as location, Service Level Agreement (SLA), machines, and a list of those technicians who usually deliver maintenance interventions is now fruitfully used to customize the service offering, creating new proposals tailored on their characteristics. For example, the same technician could be sent every time to the same customer, improving the knowledge level on the customer and machine issues. The proposal of new product-service contract bundles would be supported by historical data recorded about service timings and related costs. Different types of SLA-based contracts could be proposed according to the machines and customers characteristics. This is particularly importance considering the different PSS offerings, where the bond between machines and associated services could differ consistently depending on the way they are sold and perceived by customers. 


\section{Conclusions}

The transition toward advanced PSS business models without incurring in the service paradox trap is not an easy task for a company. To this purpose, a dual perspective workflow for maintenance delivery improvement, based on the analysis of asset and its maintenance process data is proposed, and a case study shortly described. The analysis of the as is maintenance delivery process of the company demonstrated the presence of criticalities, and improvements were conducted both on the process and asset sides. If on the asset side, FMECA and machine learning approaches has been applied to identify and analyse critical components (e.g. for the analysis of the belt power absorption), on the process side, a traditional tool used to collect data on maintenance intervention, namely the Service Card, has been re-engineered to make it more user-friendly and enable a systematized data collection, favoring the subsequent analyses. A structured database has been created to store data from maintenance in the scope of using them to improve the service offering. Despite the results achieved, the transition of Balance Systems towards PSS is only at the beginning.

In conclusion, the profitable offering of corrective, preventive or predictive maintenance is strictly subjected to the capacity of the company to exploit data from both the maintenance delivery process and product, allowing the company to improve its efficiency and make the right decision supported by data. In this sense, the role played by technologies, as machine learning techniques, is crucial since they are a support for a more formalized data collection, management, and analysis.

Concerning limitations, the workflow and case study developed in the paper could be improved in different ways. Regarding the workflow, a more detailed analysis of methods and tools supporting the different phases should be carried out, providing some guidelines to help companies in selecting the most suitable ones. Regarding the case study, the first two parts of the workflow has been applied to a single company with the aim of formalizing the data collection and management phases both regarding the asset and the maintenance delivery.

Future developments require to carry out a cross-analysis phase (when a good set of data will be available) which should enable a consistent update of the asset and process information as well as a better understanding of the tools more suitable for inferring decisions on the service maintenance strategies and policies to adopt and supporting the definition of new contracts customized on both the machines and the customer's needs.

\section{Acknowledgements}

This research is supported by Lombardy Region - FESR 2014-2020 innovazione e competitività "Bando Linea R\&S per aggregazioni" in the project "Proactive Maintenance and rEal Time monitoring for Efficiency \& Ø defect production (PROMETEØ)", project ID: 148633, CUP: E47H16001570009.

The authors are thankful to the project partner Balance Systems for the support given in the execution of the research and the information therein provided. 


\section{References}

1. Cavalieri, S., Pezzotta, G. (2012) Product-service systems engineering: State of the art and research challenges. Comput Ind 63, 278-288.

2. Gebauer, H., Fleisch, E., Friedli, T. (2005) Overcoming the service paradox in manufacturing companies. Eur Manag J 23, 14-26.

3. Baines, T., Lightfoot, H., Evans, S., et al. (2007) State-of-the-art in product-service systems. Proc Inst Mech Eng Part B J Eng Manuf 221, 1543-1552.

4. Tukker, A. (2004) Eight Types of Product-Service System: Eight Ways to Sustainability? Experiences from Suspronet. Bus Strateg Environ 13, 246-260.

5. Gaiardelli, P., Resta, B., Martinez, V., et al (2014) A classification model for productservice offerings. J Clean Prod 66, 507-519.

6. Neely, A. (2008) Exploring the Financial Consequences of the Servitization of Manufacturing. Oper Manag Res Oper Manag Res Oper Manag Res 1, 1-50.

7. Avadikyan, A., Lhuillery, S., Negassi, S. (2016) Technological innovation, organizational change, and product-related services. M@n@gement 19, 277.

8. Ardolino, M., Rapaccini, M., Saccani, N., et al. (2017) The role of digital technologies for the service transformation of industrial companies. Int J Prod Res, 1-17.

9. Bagozi, A., B, DB., Antonellis, V. De, et al. (2018) On the Move to Meaningful Internet Systems. OTM 2017 Workshops. 10697, 429-447.

10. Tao, F., Qi, Q. (2017) New IT Driven Service-Oriented Smart Manufacturing: Framework and Characteristics. IEEE Trans Syst Man, Cybern Syst, 1-11.

11. Mahlamäki, K., Niemi, A., Jokinen, J., Borgman, J. (2016) Importance of maintenance data quality in extended warranty simulation. Int J COMADEM 19, 3-10.

12. Emmanouilidis, C., Pistofidis, P., Bertoncelj, L., et al. (2019) Enabling the human in the loop: Linked data and knowledge in industrial cyber-physical systems. Annu Rev Control.

13. Lagemann, H., Boßlau, M., Meier, H. (2015) The influence of dynamic business models on IPS2 network planning - An agent-based simulation approach. Procedia CIRP 30, 102-107.

14. Wittenberg, C. (2016) Human-CPS Interaction - requirements and human-machine interaction methods for the Industry 4.0. IFAC-PapersOnLine 49, 420-425.

15. Chen, Y., Ye, C., Liu, B., Kang, R. (2012) Status of FMECA research and engineering application. Proc IEEE 2012 Progn Syst Heal Manag Conf PHM-2012, 1-9.

16. Tran, VT., Thom Pham, H., Yang, BS., Tien Nguyen, T. (2012)Machine performance degradation assessment and remaining useful life prediction using proportional hazard model and support vector machine. Mech Syst Signal Process 32:320-330.

17. Susto, GA., Schirru, A., Pampuri, S., et al. (2015) Machine Learning for Predictive Maintenance: A Multiple Classifier Approach. IEEE Trans Ind Informatics 11, 812820. 